\title{
Differential expression profiles of microRNAs as potential biomarkers for the early diagnosis of esophageal squamous cell carcinoma
}

\author{
MIAO YANG ${ }^{1 *}$, RAN LIU $^{1 *}$, JINGYI SHENG $^{1}$, JUAN LIAO $^{1}$, YI WANG ${ }^{2}$, \\ ENCHUN PAN $^{2}$, WEI GUO ${ }^{3}$, YUEPU PU ${ }^{1}$ and LIHONG YIN ${ }^{1}$
}

${ }^{1}$ Key Laboratory of Environmental Medicine Engineering, Ministry of Education, School of Public Health,
Southeast University, Nanjing, Jiangsu 210009; ${ }^{2}$ Huaian Center for Disease Control and Prevention,
Huaian, Jiangsu 223001; ${ }^{3}$ The First People's Hospital of Huaian, Huaian, Jiangsu 223000, P.R. China

Received August 22, 2012; Accepted October 2, 2012

DOI: 10.3892/or.2012.2105

\begin{abstract}
Esophageal squamous cell carcinoma (ESCC) is one of the most lethal malignancies worldwide. To reduce the high morbidity and mortality of the disease, sensitive and specific biomarkers for early detection are urgently needed. Tumor-specific microRNAs (miRNAs) seem to be potential biomarkers for the early diagnosis and treatment of cancer. In this study, differentially expressed miRNAs in tumor tissues and adjacent non-tumor tissues were detected by miRNA microarrays. Stem-loop real-time reverse transcription PCR was conducted to verify the candidate miRNAs discovered by microarray analysis. The data showed that hsa-miR-338-3p, hsa-miR-218 and hsa-miR-139-5p were downregulated in tumor tissues compared with adjacent non-tumor tissues, while hsa-miR-183, hsa-miR-574-5p, hsa-miR-21* and hsa-miR-601 were upregulated in tumor tissues. Multiple regression analysis revealed the aberrant expression of hsa-miR-338-3p, hsa-miR139-5p, hsa-miR-574-5p and hsa-miR-601 increased the risk of esophageal cancer. Furthermore, we found hsa-miR-21* was significantly increased in heavy drinking patients. Therefore, there is a set of differentially expressed miRNAs in esophageal cancer which may be associated with the incidence and development of ESCC. Differential expression profiles of miRNAs in ESCC may be promising biomarkers for the early screening of high-risk populations and early detection.
\end{abstract}

Correspondence to: Professor Lihong Yin, Key Laboratory of Environmental Medicine Engineering, Ministry of Education, School of Public Health, Southeast University, 87 Dingjiaqiao Street, Nanjing, Jiangsu 210009, P.R. China

E-mail: 1hyin@seu.edu.cn

${ }^{*}$ Contributed equally

Key words: esophageal carcinoma, microRNA, microarray, profile

\section{Introduction}

Esophageal squamous cell carcinoma (ESCC) is one of the most common types of cancer worldwide. In China, ESCC remains one of the leading causes of cancer-related mortality in some high-risk areas. According to the data from the disease control and prevention center of Jiangsu Province, cancer was the leading cause of mortality for Jiangsu inhabitants in 2007, and esophageal cancer ranked the first cause of cancer-related mortality (1). Moreover, the disease is very often diagnosed at advanced stages, resulting in poor prognosis. Despite significant investment and advances in the treatment of the disease, the overall survival for advanced and metastatic cancer remains dismal, with a 5-year survival rate of less than $30 \%$ (2). To improve the situation, there is an urgent need for novel and reliable biomarkers for ESCC. Huaian in China is an area with high ESCC morbidity and mortality rates. The specific genes of the population in this area and geographical environment may bring some distinguishing features of ESCC.

In recent years, several studies have confirmed that aberrant expression of miRNAs may be involved in the initiation and progression of human cancer (3). microRNAs (miRNAs) are a class of small (18-22 nt) non-coding RNA molecules which can regulate gene expression at the post-transcriptional level by targeting mRNAs, and inhibit the translation and/or degrade the mRNAs (4). Accumulating evidence indicates that the dysregulation of miRNAs may be a key event in human cancer (5-8). miRNA expression profiles could be used for the prediction of cancer risk, as well as for the early diagnosis, histologic classification and prognosis prediction, mainly because miRNAs are highly conservative and tissue-specific (9). There have already been some studies on miRNA expression profiles in Barrett's esophagus and esophageal adenocarcinoma $(10,11)$. However, there is little information on miRNA profiles in ESCC. In the present study, differential expression profiles of miRNAs in ESCC in the Huaian population were determined with tumor tissues and adjacent non-tumor tissues from 138 newly diagnosed patients. 


\section{Materials and methods}

Specimen collection and ethics statement. Three male patients aged 61, 71 and 62 were recruited for miRNA microarray analysis, and 138 patients, including 95 males and 43 females aged between $40-83$ years, were recruited for quantitative RT-PCR analysis from the First People's Hospital of Huaian between 2009 and 2010, with their consent and agreement. During the recruitment, each patient was interviewed using a structured questionnaire, including demographic data and epidemiological behavior such as dietary habits, smoking status and alcohol consumption. All patients were confirmed by pathology or endoscopy as ESCC without preoperative radiotherapy or chemotherapy. Esophageal cancer tissues and adjacent non-tumor tissues were obtained from surgical specimens immediately after resection from patients. The adjacent non-tumor esophageal epithelium was located at least $5 \mathrm{~cm}$ away from tumor edge. Tissue samples $\left(0.5 \mathrm{~cm}^{3}\right)$ were immersed in RNA locker (Tiandz, China) at $4^{\circ} \mathrm{C}$ overnight and stored at $-20^{\circ} \mathrm{C}$ until use. This study was approved by the institutional review board 'IRB of Southeast University Affiliated Zhongda Hospital' in Nanjing, China. The design of the esophageal cancer study, including the tissue sample collection, was approved by the IRB.

RNA isolation. Total-RNA was extracted from both the esophageal cancer tissues and adjacent non-tumor esophageal epithelium using TRIzol reagent (Invitrogen, USA) according to the instructions. Concentration and integrity of extracted RNA was assessed using a NanoDrop 1000 spectrophotometer (NanoDrop Technologies, USA). Finally, the total-RNA integrity was checked by denaturing agarose gel electrophoresis.

miRNA microarray. Three pairs of esophageal cancer samples were collected for microarray analysis. Agilent human miRNA microarray (V12.0, Agilent, USA) was used in this study. Samples of miRNA from 6 esophageal specimens were labeled and hybridized with the miRNA Complete Labeling and Hybridization kit (Agilent) according to the manufacturer's protocol. Signals were normalized using the median center tool for genes. Statistical analysis of ANOVA was used to compare the differentially expressed miRNAs.

Quantitative reverse transcription PCR. In this study, U6 was chosen as the endogenous standard. Reverse transcription reactions were conducted in two steps. First, the mixture containing $0.5 \mu \mathrm{g}$ of RNA samples, $1 \mu \mathrm{l}$ miRNA-specific stem-loop RT primers (RiboBio, China) and RNase-free water (Tiangen, China) was incubated in a 96 -well plate for $10 \mathrm{~min}$ at $70^{\circ} \mathrm{C}$ and held at $4^{\circ} \mathrm{C}$. Then, the $12.5 \mu \mathrm{l}$ mixture which comprised $5.5 \mu \mathrm{l}$ RT product (obtained from the front), $2.5 \mu \mathrm{l} 5 \mathrm{X}$ RT buffer (Promega, USA), $1 \mu \mathrm{l}$ dNTPs (2.5 mM) (Tiangen, China), $0.25 \mu \mathrm{l}$ MMLV reverse transcriptase $(200 \mathrm{U} / \mu \mathrm{l})$ (Promega, USA), $0.25 \mu 1$ ribonuclease inhibitor (40 U/ $\mu \mathrm{l})$ (Fermentas,

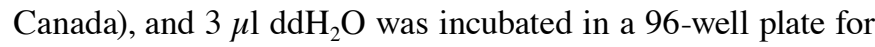
$1 \mathrm{~h}$ at $42^{\circ} \mathrm{C}$, for $10 \mathrm{~min}$ at $70^{\circ} \mathrm{C}$ and subsequently held at $4{ }^{\circ} \mathrm{C}$.

Real-time PCR was carried out to detect the expression levels of candidate miRNAs with the ABI 7300 Real-Time PCR System (Applied Biosystems, USA). qRT-PCR was then performed using SYBR ${ }^{\circledR}$ Green Real-time PCR Master
Table I. Differential expression of miRNAs in ESCC tumor tissues vs. non-tumor tissues by microarray.

\begin{tabular}{llcl}
\hline Systematic name & P-value & Fold-change & Regulation \\
\hline hsa-miR-20a & 0.008602 & 1.123039 & $\mathrm{Up}$ \\
hsa-miR-155 & 0.02269 & 1.829959 & $\mathrm{Up}$ \\
hsa-miR-574-5p & 0.036782 & 1.716395 & $\mathrm{Up}$ \\
hsa-miR-21* & 0.049597 & 2.597901 & $\mathrm{Up}$ \\
hsa-miR-183 & 0.035308 & 2.250472 & $\mathrm{Up}$ \\
hsa-miR-601 & 0.020643 & 1.673934 & $\mathrm{Up}$ \\
hsa-miR-623 & 0.045492 & 1.635291 & $\mathrm{Up}$ \\
hsa-miR-139-5p & 0.01244 & 9.728012 & Down \\
hsa-miR-10a & 0.00732 & 1.424195 & Down \\
hsa-miR-144 & 0.039268 & 13.40895 & Down \\
hsa-miR-338-3p & 0.019786 & 2.29184 & Down \\
hsa-miR-192 & 0.02489 & 5.695984 & Down \\
hsa-miR-218 & 0.021029 & 4.956112 & Down \\
hsa-miR-451 & 0.004967 & 1.425921 & Down \\
hsa-miR-186 & $9.79 \mathrm{E}-05$ & 6.050884 & Down \\
\hline
\end{tabular}

Mix-Plus (Toyobo, Japan) according to the manufacturer's protocol. The PCR reaction components were $1 \mu 1$ of cDNA, $4.5 \mu 1$ of SYBR-Green PCR Master mix, $5 \mathrm{mmol} / \mathrm{l} \mathrm{PCR}$ primers (RiboBio, China) and RNase-free water. The reaction was performed at $95^{\circ} \mathrm{C}$ for $5 \mathrm{~min}$, followed by 40 cycles of $95^{\circ} \mathrm{C}$ for $15 \mathrm{sec}, 60^{\circ} \mathrm{C}$ for $30 \mathrm{sec}$ and $72^{\circ} \mathrm{C}$ for $30 \mathrm{sec}$. Dissociation curve was analyzed from 60 to $99^{\circ} \mathrm{C}$.

Data analysis. Data analyses were performed using the SPSS, version 18.0. $\mathrm{P}<0.05$ was considered to indicate statistically significant differences. We applied the paired t-test and conditional logistic regression analysis to determine the statistical differences between tumor tissues and adjacent non-tumor tissues. miRNA expression was calculated using the $2^{-\Delta \Delta \mathrm{Ct}}$ method (12), where $\Delta \mathrm{Ct}=\left(\mathrm{Ct}_{\text {miRNA }}-\mathrm{Ct}_{\mathrm{u} 6}\right)$ and $\Delta \Delta \mathrm{Ct}=\Delta \mathrm{Ct}_{\text {tumor }}$ tissues $-\Delta \mathrm{Ct}_{\text {adjacent non-tumor tissues }}$. The threshold cycle (12) indicates the fractional cycle number at which the amount of amplified target reaches a fixed threshold and the $\mathrm{Ct}$ value is negatively correlated with copy numbers (12). Thus, in the final calculation, the $\mathrm{Ct}$ values are multiplied with -1 for logistic regression analysis. Student's t-test analysis and analysis of variance (ANOVA) were applied to determine the differences of miRNA expression in different environmental factors.

\section{Results}

Screening of candidate miRNAs by miRNA microarray. Microarray analysis identified 15 miRNAs that could distinguish the malignant esophageal cancer lesions from the adjacent non-tumor tissues. A total of 7 miRNAs were found overexpressed in tumor tissues (hsa-miR-20a, hsa-miR-155, hsa-miR-574-5p, hsa-miR-21*, hsa-miR-183, hsa-miR-601 and hsa-miR-623). Whereas, hsa-miR-186, hsa-miR-10a, hsa-miR-144, hsa-miR-338-3p, hsa-miR-192, hsa-miR-218, hsa-miR-451, hsa-miR-139-5p were found downregulated 


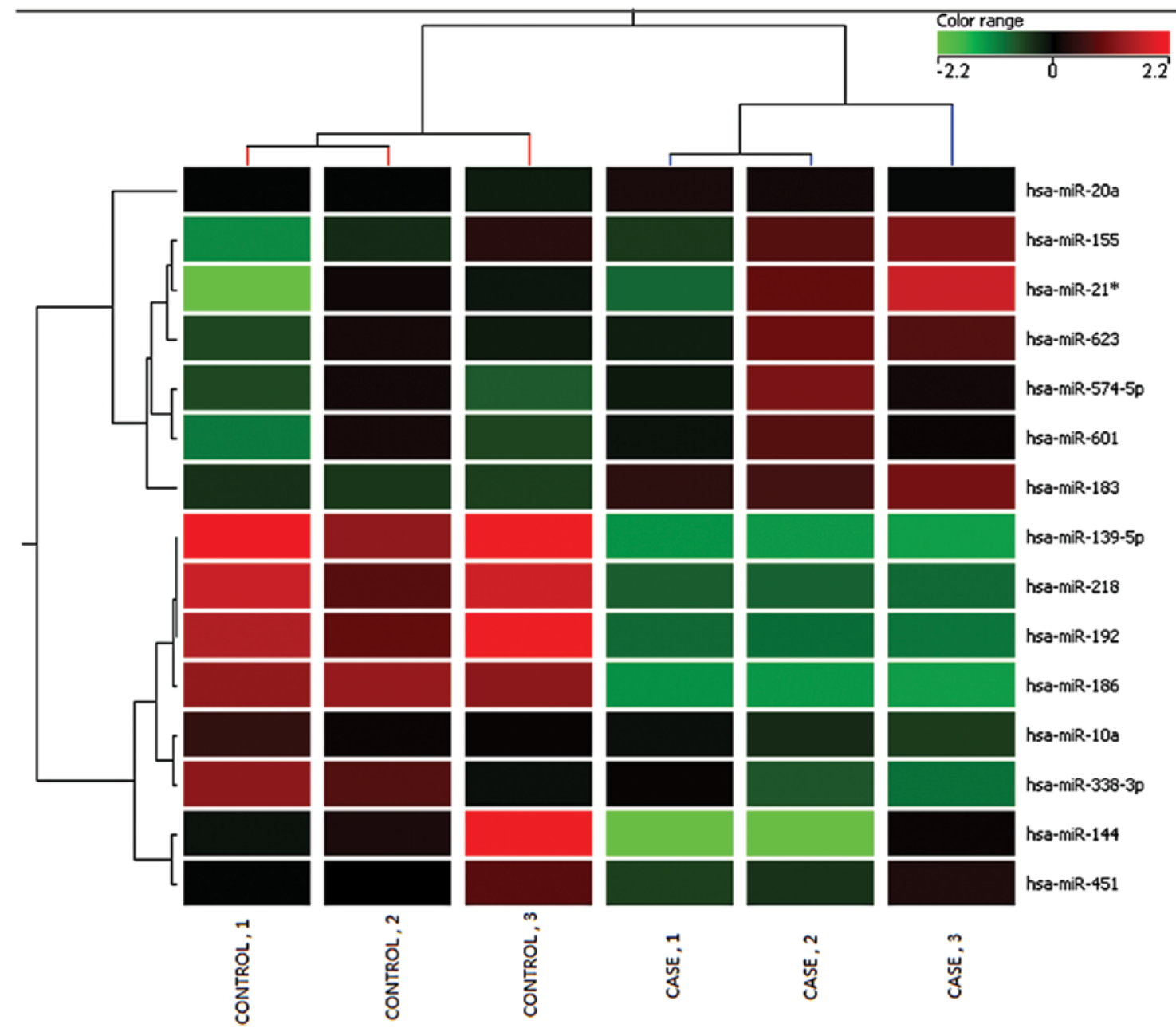

Figure 1. Cluster analysis of differentially expressed miRNAs in tumor tissues vs. adjacent non-tumor tissues. The result of hierarchical clustering shows a distinguishable gene expression profiling between samples. The rows show 15 differentially expressed miRNAs, while the columns show 3 paired samples. Red represents a high expression and green represents a low expression.

(Table I). Cluster analysis, based on the differentially expressed miRNAs, successfully separated the tumor tissues from the adjacent non-tumor tissues (Fig. 1). The analysis showed the chips in each case were consistent.

Validation of microarray data by quantitative RT-PCR analysis. To confirm the microarray results, we performed quantitative RT-PCR analysis on larger samples. The expression data obtained by quantitative RT-PCR analysis were comparable to the results observed in the microarray analysis. The results of hsa-miR-338-3p, hsa-miR-144, hsa-miR-192, hsa-miR-218 and hsa-miR-139-5p showed the consistency of the downregulation compared with microarray, while hsa-miR-20a, hsa-miR-155, hsa-miR-574-5p, hsa-miR-183, hsa-miR-21* and hsa-miR-601 showed the consistency of upregulation. The histogram (Fig. 2) is shown with the fold-changes of real-time RT-PCR $\left(2^{-\Delta \Delta \mathrm{Ct}}\right)$ and miRNA microarray. The consistency of microarray and real-time RT-PCR confirmed the reliability of the results.

Differential expression of miRNAs between the tumor tissues and the adjacent non-tumor tissues. We applied the paired $\mathrm{t}$-test to assess the differences between the tumor tissues and the adjacent non-tumor tissues shown in Table II. The results showed that hsa-miR-139-5p, hsa-miR-218 and hsa-miR338 -3p (fold-change $=0.106,0.623,0.239$, respectively) were downregulated in tumor tissues when compared with adjacent non-tumor tissues, while hsa-miR-21*, hsa-miR-574-5p, hsa-miR-183 and hsa-miR-601 (fold-change $=1.863,1.603$, $2.096,1.763$, respectively) were upregulated in tumor tissues.

Association between candidate miRNAs and the risk of ESCC. Conditional logistic regression analysis was used to evaluate the association between differentially expressed miRNAs and the risk of esophageal cancer. As shown in Table III, significantly increased risk for esophageal cancer was associated with reduced expression of hsa-miR-139-5p and hsa-miR-338-3p $(\mathrm{OR}=0.599,0.720$, respectively) and increased expression of hsa-miR-21*, hsa-miR-574-5p, hsa-miR-183, hsa-miR-601 $(\mathrm{OR}=1.135,1.113,1.142,1.492$, respectively). This suggested that hsa-miR-21*, hsa-miR-574-5p, hsa-miR-183, hsa-miR-601 may function as oncogenes, while hsa-miR-139-5p and hsa-miR-338-3p might act as tumor suppressors.

Multiple regression analysis was used to determine the association between the differentially expressed miRNAs (hsa-miR-139-5p,hsa-miR-338-3p,hsa-miR-21*,hsa-miR-574-5p, 


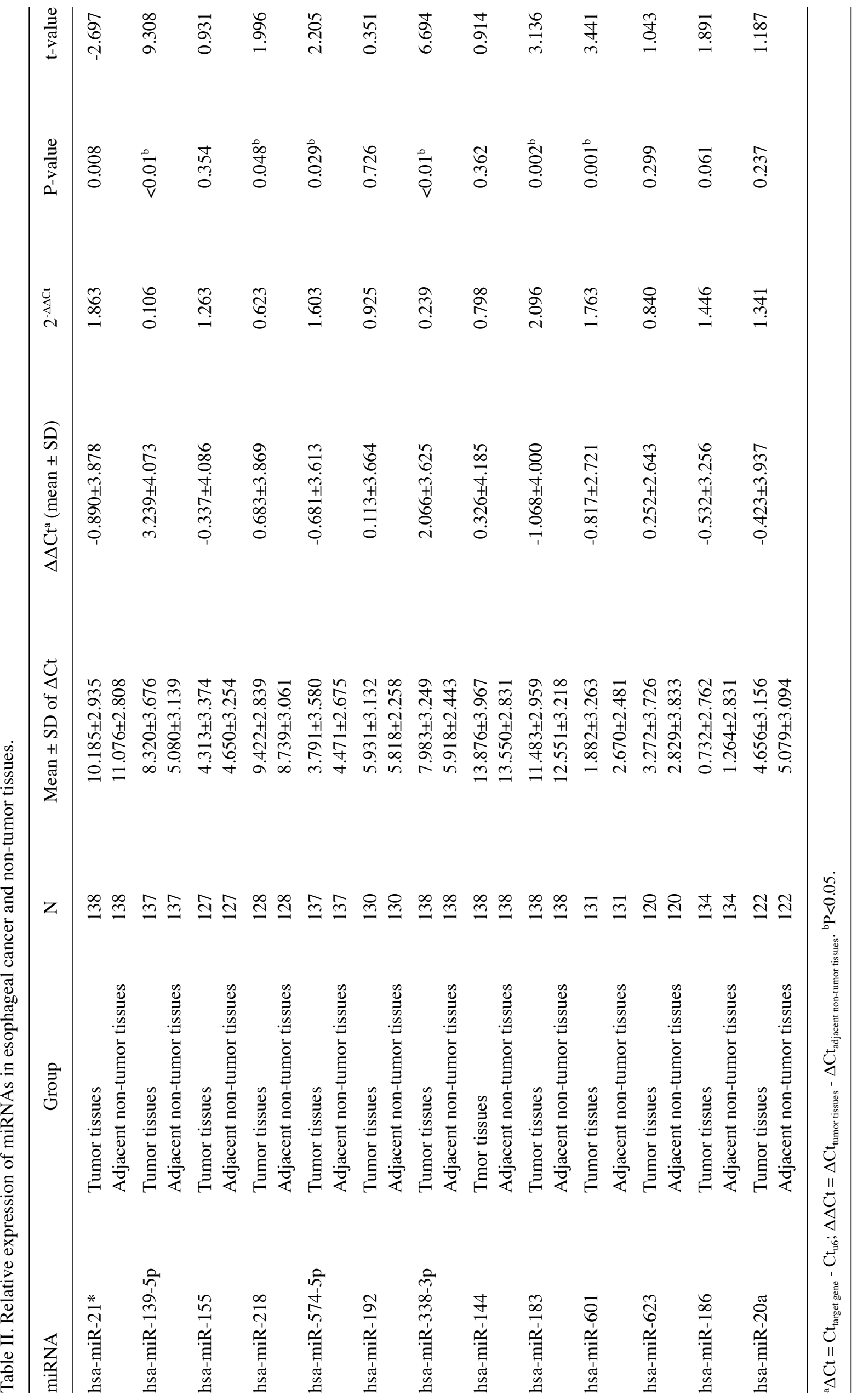




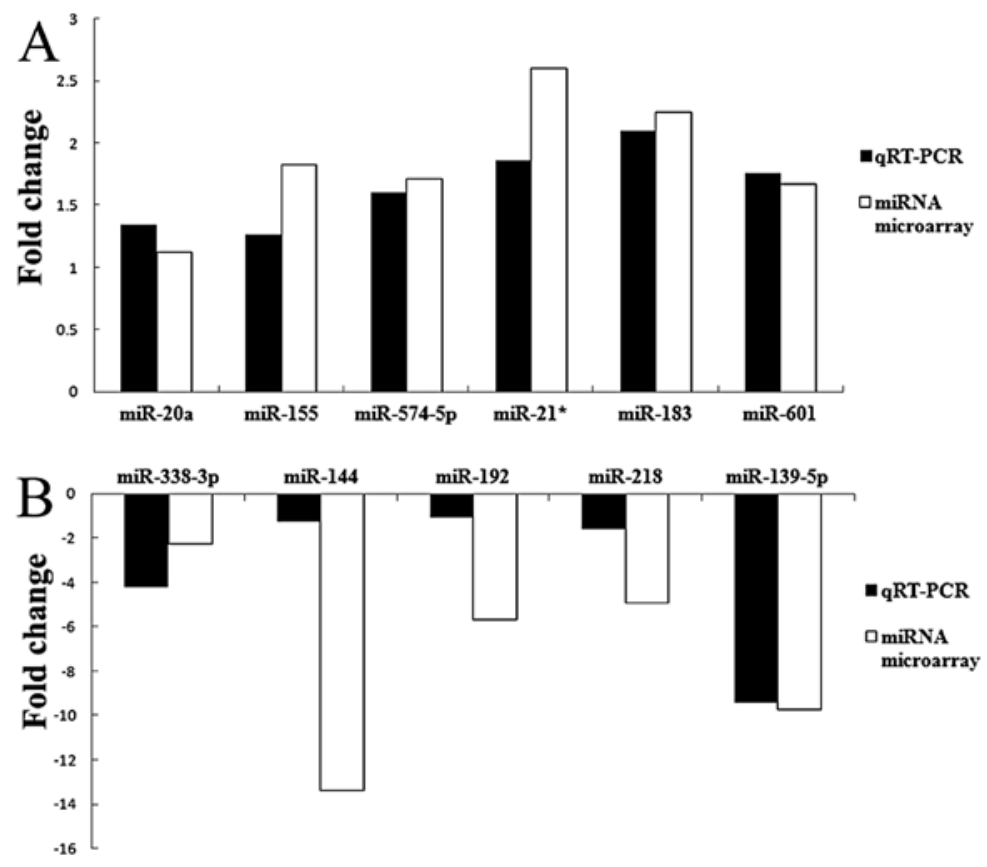

Figure 2. Differentially expressed miRNAs analyzed by miRNA microarray and real-time RT-PCR. (A) The expression level of upregulated miRNAs identified by miRNA microarray and real-time RT-PCR. (B) The expression level of downregulated miRNAs identified by miRNA microarray and real-time RT-PCR. The data was analyzed according to the fold-changes of real-time RT-PCR $\left(2^{-\Delta \Delta C t}\right)$ and miRNA microarray. If the fold-change is $<1$, the reciprocal is taken, otherwise the original value is taken.

Table III. Aberrant expression of miRNAs associated with a high risk of ESCC by conditional logistic regression analysis.

\begin{tabular}{|c|c|c|c|c|c|c|c|}
\hline miRNA & Group & $\beta$ & SE & Wald & P-value & OR & $95 \% \mathrm{CI}$ \\
\hline hsa-miR-21* & $\begin{array}{l}\text { Tumor tissues } \\
\text { Adjacent non-tumor tissues }\end{array}$ & 0.126 & 0.049 & 6.643 & $0.010^{\mathrm{a}}$ & $\begin{array}{l}1.135 \\
1.000\end{array}$ & $1.031-1.249$ \\
\hline hsa-miR-139-5p & $\begin{array}{l}\text { Tumor tissues } \\
\text { Adjacent non-tumor tissues }\end{array}$ & -0.512 & 0.084 & 37.006 & $0.000^{\mathrm{a}}$ & $\begin{array}{l}0.599 \\
1.000\end{array}$ & $0.508-0.707$ \\
\hline hsa-miR-155 & $\begin{array}{l}\text { Tumor tissues } \\
\text { Adjacent non-tumor tissues }\end{array}$ & 0.041 & 0.045 & 0.850 & 0.357 & $\begin{array}{l}1.042 \\
1.000\end{array}$ & $0.955-1.137$ \\
\hline hsa-miR-218 & $\begin{array}{l}\text { Tumor tissues } \\
\text { Adjacent non-tumor tissues }\end{array}$ & -0.094 & 0.048 & 3.732 & 0.053 & $\begin{array}{l}0.911 \\
1.000\end{array}$ & $0.828-1.001$ \\
\hline hsa-miR-574-5p & $\begin{array}{l}\text { Tumor tissues } \\
\text { Adjacent non-tumor tissues }\end{array}$ & 0.107 & 0.050 & 4.510 & $0.034^{\mathrm{a}}$ & $\begin{array}{l}1.113 \\
1.000\end{array}$ & $1.008-1.228$ \\
\hline hsa-miR-192 & $\begin{array}{l}\text { Tumor tissues } \\
\text { Adjacent non-tumor tissues }\end{array}$ & -0.017 & 0.048 & 0.125 & 0.724 & $\begin{array}{l}0.983 \\
1.000\end{array}$ & $0.894-1.081$ \\
\hline hsa-miR-338-3p & $\begin{array}{l}\text { Tumor tissues } \\
\text { Adjacent non-tumor tissues }\end{array}$ & -0.329 & 0.065 & 25.987 & $0.000^{\mathrm{a}}$ & $\begin{array}{l}0.720 \\
1.000\end{array}$ & $0.634-0.817$ \\
\hline hsa-miR-144 & $\begin{array}{l}\text { Tumor tissues } \\
\text { Adjacent non-tumor tissues }\end{array}$ & -0.038 & 0.041 & 0.834 & 0.361 & $\begin{array}{l}0.963 \\
1.000\end{array}$ & $0.889-1.044$ \\
\hline hsa-miR-183 & $\begin{array}{l}\text { Tumor tissues } \\
\text { Adjacent non-tumor tissues }\end{array}$ & 0.133 & 0.045 & 8.737 & $0.003^{\mathrm{a}}$ & $\begin{array}{l}1.142 \\
1.000\end{array}$ & $1.046-1.247$ \\
\hline hsa-miR-601 & $\begin{array}{l}\text { Tumor tissues } \\
\text { Adjacent non-tumor tissues }\end{array}$ & 0.400 & 0.110 & 13.221 & $0.000^{\mathrm{a}}$ & $\begin{array}{l}1.492 \\
1.000\end{array}$ & $1.203-1.852$ \\
\hline hsa-miR-623 & $\begin{array}{l}\text { Tumor tissues } \\
\text { Adjacent non-tumor tissues }\end{array}$ & -1.010 & 0.080 & 1.593 & 0.207 & $\begin{array}{l}0.904 \\
1.000\end{array}$ & $0.773-1.058$ \\
\hline hsa-miR-186 & $\begin{array}{l}\text { Tumor tissues } \\
\text { Adjacent non-tumor tissues }\end{array}$ & 0.102 & 0.055 & 3.394 & 0.065 & $\begin{array}{l}1.107 \\
1.000\end{array}$ & $0.994-1.234$ \\
\hline hsa-miR-20a & $\begin{array}{l}\text { Tumor tissues } \\
\text { Adjacent non-tumor tissues }\end{array}$ & 0.055 & 0.047 & 1.379 & 0.240 & $\begin{array}{l}1.057 \\
1.000\end{array}$ & $0.964-1.159$ \\
\hline
\end{tabular}

${ }^{\mathrm{a}} \leq 0.05$. 
Table IV. Aberrant expression of miRNAs associated with a high risk of ESCC by multiple regression analysis.

\begin{tabular}{lcccccc}
\hline Variables & $\beta$ & SE & Wald & P-value & OR & $95 \%$ CI \\
\hline hsa-miR-338-3p & -0.788 & 0.171 & 21.180 & 0.000 & 0.455 & $0.325-0.636$ \\
hsa-miR-139-5p & -0.695 & 0.183 & 14.352 & 0.000 & 0.499 & $0.349-0.715$ \\
hsa-miR-574-5p & 0.732 & 0.165 & 19.627 & 0.000 & 2.079 & $1.504-2.873$ \\
hsa-miR-601 & 0.174 & 0.086 & 4.108 & 0.043 & 1.191 & $1.006-1.409$ \\
\hline
\end{tabular}

hsa-miR-183 and hsa-miR-601) which showed significance in logistic regression analysis and the risk of esophageal cancer. The results revealed that hsa-miR-601 and hsa-miR-574-5p were positively associated with increased risk of ESCC (OR=1.191, 2.079, respectively), whereas hsa-miR-338-3p and hsa-miR-139-5p were negatively associated with increased risk of ESCC (OR=0.455, 0.499, respectively) (Table IV).

Environmental factors and miRNA expression. We then analyzed the association between miRNA expression and environmental factors of ESCC patients including tobacco smoking, alcohol consumption and drinking water source. As shown in Table $\mathrm{V}$, the results revealed that hsa-miR-21*was associated with alcohol consumption. High expression of hsa-miR-21* was prone to be observed in heavy drinking patients compared with non-drinkers or occasional drinkers $(\mathrm{P}=0.046)$.

\section{Discussion}

miRNAs have been studied extensively in recent years for their involvement in tumorigenesis and their potential as biomarkers in the diagnosis, prognosis and treatment of cancer (13). Chen et al (14) analyzed the expression profile of serum miRNAs in 400 non-small cell lung cancer (NSCLC) cases and 220 controls and identified 10 miRNAs as potential markers for early diagnosis of NSCLC. Hu et al (15) assayed the expression of 10 miRNAs in 10 esophageal cancer cell lines and 158 tissue specimens and found that miR-30e and miR-16-2 were associated with overall and disease-free survival. Wiggins et al (16) evaluated miRNA replacement therapy of miR-34a in lung tumors in mice. These studies provide sound evidence that altered miRNAs could be reliable biomarkers for the early detection and prognosis prediction of cancer.

To date, there have already been published data on miRNA profiles in esophageal cancer. In a previous study, Guo et al (17) revealed that 46 miRNAs expressed differently in 31 pairs of cryopreserved ESCC tissues and non-tumor tissues using miRNA microarray techniques and 7 of them could distinguish tumor tissues from non-tumor tissues. Ogawa et al (18) analyzed the expression of 73 miRNAs in 30 pairs of ESCC tumor and adjacent non-tumor tissues by RT-PCR, and they found that the high expression of miR-129 was associated with shorter postoperative survival. Feber et al (19) reported that in 35 frozen specimens (10 adenocarcinoma, 10 squamous cell carcinoma, 9 normal epithelium, 5 Barrett esophagus, and 1 high-grade dysplasia) several differentially expressed miRNAs could distinguish different esophageal histologic types and also discriminate tumor from normal esophageal tissues in both adenocarcinoma and squamous cell carcinoma. These studies indicate that specific miRNA profiles of ESCC may bring breakthroughs to the diagnosis and treatment of ESCC.

We analyzed the expression of 13 miRNAs in 138 pairs of tumor tissues and adjacent non-tumor tissues by using quantitative RT-PCR. Among them, hsa-miR-338-3p, hsa-miR-218 and hsa-miR-139-5p were downregulated in tumor tissues vs. adjacent non-tumor tissues, whereas hsa-miR-183, hsa-miR-574-5p, hsa-miR-21* and hsa-miR-601 were upregulated in tumor tissues.

hsa-miR-139-5p, hsa-miR-218 and hsa-miR-338-3p downregulated in the present study were found as tumor suppressors in several studies. hsa-miR-139-5p has previously been described as downregulated in many types of cancer, including gastric cancer, renal tumors and endometrial serous adenocarcinomas and bladder cancer (20-23). It has been proposed that hsa-miR-139-5p may have various functions in different types of cancer. Hiroki et al (22) showed the lower expression of hsa-miR-139-5p was significantly correlated with poor overall survival in endometrial serous adenocarcinoma. Miles et al (24) suggested a direct causal dysregulation of TOP2A by hsa-miR-139-5p, and TOP2A may be a drug target in ovarian cancer. In addition, the tumor suppressor function of hsa-miR-139-5p being epigenetically silenced by enhancer of zeste homolog 2 (EZH2) may lead to liver cancer metastasis (25). hsa-miR-218 is also found to be a tumor suppressor in cervical, bladder and gastric cancer (26-28). hsa-miR-338-3p was considered to suppress cell invasion by targeting the smoothened gene in liver cancer (29). hsa-miR-338-3p was also found aberrantly expressed in pancreatic neoplasias (30).

A miRNA upregulated in cancer may act as an oncogene. hsa-miR-183, hsa-miR-574-5p, hsa-miR-21* and hsa-miR-601 were upregulated in tumor tissues compared with adjacent nontumor tissues in the present study. hsa-miR-574-5p was found increased in lung cancer tissues compared with controls (31) which is consistent with our findings. Yao et al (32) showed that hsa-miR-601 was highly expressed in gastric cancer compared to normal gastric tissues. hsa-miR-601 negatively regulated the Fas-induced apoptosis pathway (33), which may be one of the reasons for its oncogene-like functions. The overexpression of hsa-miR-183 inhibited the migration of breast cancer cells (34). The upregulation trend was also observed in prostate carcinoma, hepatocellular carcinoma and colorectal cancer (35-37). hsa-miR-183 has been reported to promote tumor cell migration by targeting EGR1, a tumor suppressor gene (38). Li et al (39) confirmed hsa-miR-183 targeted integrin $\beta 1$ (ITGB1). ITGB1 is known to play a major role in the development of several tissues and organs $(40,41)$. These studies suggest that hsa-miR-183 is an oncogene that plays different roles in different types of cancer. 
miRNA microarray revealed upregulation of hsa-miR-20a and hsa-miR-155, whereas, hsa-miR-192 and hsa-miR-144 were downregulated. However, they did not show statistical differences in quantitative RT-PCR. Since tumor tissues in this study were matched with adjacent non-tumor tissues instead of normal tissues, some early lesions might be confounded into normal tissues, which brought slight differences of miRNA expression levels between the tumor and the non-tumor tissue group. Although these miRNAs were not identified in our study, they may still play important roles in cancer, according to numerous other studies. hsa-miR-20a has been reported to act as a tumor suppressor by targeting and reducing E2F1 levels, and the E2F family of transcription factors is essential in the regulation of the cell cycle and apoptosis (42). hsa-miR-155 is overexpressed in various tumors, including breast, lung and pancreatic cancer (43-45). Moreover, high expression of hsa-miR-155 is considered to predict a poor prognosis of lung cancer and pancreatic tumor $(44,45)$. hsa-miR-155 may be a potential target in breast therapy (46); hsa-miR-192 and hsa-miR-144 were found decreased in many tumors, including bladder, colorectal cancer, and follicular thyroid carcinoma (47-49). The differentially expressed miRNAs found in the present study are slightly different from previous studies. Since ESCC is a result of interplays between different exposures and host susceptibilities, the Huaian population may have distinctive characteristics leading to a specific miRNA profile.

Furthermore, we found the expression of hsa-miR-21* was different in patients with alcohol consumption. Wang et al (50) found 14 miRNAs differentially expressed in fetal mouse brains with and without prenatal ethanol exposure. Soares et al (51) exposed zebra fish embryos to ethanol and altered expressions of miRNAs were observed. These studies indicate that ethanol can regulate miRNA expression. Although there are few published studies on the function of hsa-miR-21*, we found ethanol exposure can trigger alteration in hsa-miR-21* expression levels. It has been documented that ethanol alters the activities of various signal transduction pathways, including the MAPK pathway, which regulate the activities of transcription factors and, thus alter gene expression (52). MAP3K1, part of some signal transduction cascades in the MAPK/ERK pathway, is one of the targets predicted by computational analysis for hsa-miR$21 *$ (miRanda). Thereby, we speculated hsa-miR-21* may be involved in pathways of tumorigenesis induced by ethanol.

In conclusion, our study suggests a differential expression profile of miRNAs (hsa-miR-139-5p, hsa-miR-574-5p, hsa-miR-338-3p, hsa-miR-218, hsa-miR-183, hsa-miR-21* and hsa-miR-601) in ESCC. The overexpression of hsa-miR-21* was associated with alcohol consumption. These results suggest that these differentially expressed miRNAs may be potential biomarkers for the early diagnosis and prognosis of ESCC.

\section{Acknowledgements}

This study was supported by the National Natural Science Foundation of China (nos. 81172747, 81072259, 30800891, 81111140396), the Research Fund for the Doctoral Program of Higher Education of China (no. 200802861045), the Natural Science Foundation of Jiangsu province, China (no. BK2010407) and the Research and Teaching Fund for the Excellent Youth Scholars of Southeast University (2009). 


\section{References}

1. Jinyi Z, Quanyong X, Ran T, Jie Y, Ping L and Ming W: Analysis on surveillance of cause death in Jiangsu province during 2007. Jiangsu J Prev Med 2008 19: 74-75, 2008.

2. Rice TW, Rusch VW, Apperson-Hansen C, et al: Worldwide esophageal cancer collaboration. Dis Esophagus 22: 1-8, 2009.

3. Calin GA and Croce CM: MicroRNA signatures in human cancers. Nat Rev Cancer 6: 857-866, 2006.

4. Ambros V: The functions of animal microRNAs. Nature 431: $350-355,2004$

5. Lu J, Getz G, Miska EA, et al: MicroRNA expression profiles classify human cancers. Nature 435: 834-838, 2005.

6. Manikandan J, Aarthi JJ, Kumar SD and Pushparaj PN: Oncomirs: the potential role of non-coding microRNAs in understanding cancer. Bioinformation 2: 330-334, 2008.

7. Schetter AJ, Heegaard NHH and Harris CC: Inflammation and cancer: interweaving microRNA, free radical, cytokine and p53 pathways. Carcinogenesis 31: 37-49, 2010.

8. Kwak PB, Iwasaki S and Tomari Y: The microRNA pathway and cancer. Cancer Sci 101: 2309-2315, 2010.

9. Ahmed FE: Role of miRNA in carcinogenesis and biomarker selection: a methodological view. Expert Rev Mol Diagn 7: 569-603, 2007

10. Kan T and Meltzer SJ: MicroRNAs in Barrett's esophagus and esophageal adenocarcinoma. Curr Opin Pharmacol 9: 727-732, 2009.

11. Yang HS, Gu J, Wang KK, et al: MicroRNA expression signatures in Barrett's esophagus and esophageal adenocarcinoma. Clin Cancer Res 15: 5744-5752, 2009.

12. Livak KJ and Schmittgen TD: Analysis of relative gene expression data using real-time quantitative PCR and the 2(T)(-Delta Delta C) method. Methods 25: 402-408, 2001.

13. Esquela-Kerscher A and Slack FJ: Oncomirs - microRNAs with a role in cancer. Nat Rev Cancer 6: 259-269, 2006.

14. Chen X, Hu ZB, Wang WJ, et al: Identification of ten serum microRNAs from a genome-wide serum microRNA expression profile as novel noninvasive biomarkers for nonsmall cell lung cancer diagnosis. Int J Cancer 130: 1620-1628, 2012.

15. Hu YX, Correa AM, Hoque A, et al: Prognostic significance of differentially expressed miRNAs in esophageal cancer. Int J Cancer 128: 132-143, 2011.

16. Wiggins JF, Ruffino L, Kelnar K, et al: Development of a lung cancer therapeutic based on the tumor suppressor microRNA-34. Cancer Res 70: 5923-5930, 2010.

17. Guo Y, Chen Z, Zhang L, et al: Distinctive microRNA profiles relating to patient survival in esophageal squamous cell carcinoma. Cancer Res 68: 26-33, 2008.

18. Ogawa R, Ishiguro H, Kuwabara Y, et al: Expression profiling of micro-RNAs in human esophageal squamous cell carcinoma using RT-PCR. Med Mol Morphol 42: 102-109, 2009.

19. Feber A, Xi L, Luketich JD, et al: MicroRNA expression profiles of esophageal cancer. J Thorac Cardiovasc Surg 135: 255-260, 2008.

20. Guo J, Miao Y, Xiao B, et al: Differential expression of microRNA species in human gastric cancer versus non-tumorous tissues. J Gastroenterol Hepatol 24: 652-657, 2009.

21. Fridman E, Dotan Z, Barshack I, et al: Accurate molecular classification of renal tumors using microRNA expression. J Mol Diagn 12: 687-696, 2010.

22. Hiroki E, Akahira J, Suzuki F, et al: Changes in microRNA expression levels correlate with clinicopathological features and prognoses in endometrial serous adenocarcinomas. Cancer Sci 101: 241-249, 2010.

23. Yoshino H, Chiyomaru T, Enokida $\mathrm{H}$, et al: The tumoursuppressive function of miR-1 and miR-133a targeting TAGLN2 in bladder cancer. Br J Cancer 104: 808-818, 2011.

24. Miles GD, Seiler M, Rodriguez L, Rajagopal G and Bhanot G: Identifying microRNA/mRNA dysregulations in ovarian cancer. BMC Res Notes 5: 164, 2012

25. Au SL, Wong CC, Lee JM, et al: Enhancer of zeste homolog 2 epigenetically silences multiple tumor suppressor microRNAs to promote liver cancer metastasis. Hepatology 56: 622-631, 2012.

26. Yu JJ, Wang Y, Dong RF, Huang XY, Ding SN and Qiu HF: Circulating microRNA-218 was reduced in cervical cancer and correlated with tumor invasion. J Cancer Res Clin Oncol 138: 671-674, 2012.

27. Tatarano S, Chiyomaru T, Kawakami K, et al: miR-218 on the genomic loss region of chromosome $4 \mathrm{p} 15.31$ functions as a tumor suppressor in bladder cancer. Int J Oncol 39: 13-21, 2011.
28. Gao CP, Zhang ZY, Liu WZ, Xiao SD, Gu WQ and Lu H: Reduced microRNA-218 expression is associated with high nuclear factor kappa B activation in gastric cancer. Cancer 116: 41-49, 2010.

29. Huang XH, Chen JS, Wang Q, et al: miR-338-3p suppresses invasion of liver cancer cell by targeting smoothened. J Pathol 225: 463-472, 2011

30. Yu J, Li A, Hong SM, Hruban RH and Goggins M: MicroRNA alterations of pancreatic intraepithelial neoplasias. Clin Cancer Res 18: 981-992, 2012.

31. Foss KM, Sima C, Ugolini D, Neri M, Allen KE and Weiss GJ: miR-1254 and miR-574-5p: serum-based microRNA biomarkers for early-stage non-small cell lung cancer. J Thorac Oncol 6 : 482-488, 2011

32. Yao Y, Suo AL, Li ZF, et al: MicroRNA profiling of human gastric cancer. Mol Med Rep 2: 963-970, 2009.

33. Ohdaira H, Nakagawa H and Yoshida K: Profiling of molecular pathways regulated by microRNA 601. Comput Biol Chem 33: 429-433, 2009.

34. Lowery AJ, Miller N, Dwyer RM and Kerin MJ: Dysregulated miR-183 inhibits migration in breast cancer cells. BMC Cancer 10: 502, 2010.

35. Schaefer A, Jung M, Mollenkopf HJ, et al: Diagnostic and prognostic implications of microRNA profiling in prostate carcinoma. Int J Cancer 126: 1166-1176, 2010.

36. Li J, Fu H, Xu C, et al: miR-183 inhibits TGF-beta1-induced apoptosis by downregulation of PDCD4 expression in human hepatocellular carcinoma cells. BMC Cancer 10: 354, 2010.

37. Bandres E, Cubedo E, Agirre X, et al: Identification by real-time PCR of 13 mature microRNAs differentially expressed in colorectal cancer and non-tumoral tissues. Mol Cancer 5: 29, 2006.

38. Sarver AL, Li LH and Subramanian S: MicroRNA miR-183 functions as an oncogene by targeting the transcription factor EGR1 and promoting tumor cell migration. Cancer Res 70: 9570-9580, 2010.

39. Li GR, Luna C, Qiu JM, Epstein DL and Gonzalez P: Targeting of integrin betal and kinesin 2alpha by microRNA 183. J Biol Chem 285: 5461-5471, 2010.

40. Kanasaki K, Kanda Y, Palmsten K, et al: Integrin beta1-mediated matrix assembly and signaling are critical for the normal development and function of the kidney glomerulus. Dev Biol 313: 584-593, 2008.

41. Wederell ED and de Iongh RU: Extracellular matrix and integrin signaling in lens development and cataract. Semin Cell Dev Biol 17: 759-776, 2006.

42. O'Donnell KA, Wentzel EA, Zeller KI, Dang CV and Mendell JT: c-Myc-regulated microRNAs modulate E2F1 expression. Nature 435: 839-843, 2005.

43. Iorio MV, Ferracin M, Liu CG, et al: MicroRNA gene expression deregulation in human breast cancer. Cancer Res 65: 7065-7070, 2005.

44. Yanaihara N, Caplen N, Bowman E, et al: Unique microRNA molecular profiles in lung cancer diagnosis and prognosis. Cancer Cell 9: 189-198, 2006.

45. Greither T, Grochola LF, Udelnow A, Lautenschlager C, Wurl P and Taubert $\mathrm{H}$ : Elevated expression of microRNAs 155, 203, 210 and 222 in pancreatic tumors is associated with poorer survival. Int J Cancer 126: 73-80, 2010.

46. Jiang SA, Zhang HW, Lu MH, et al: MicroRNA-155 functions as an OncomiR in breast cancer by targeting the suppressor of cytokine signaling 1 gene. Cancer Res 70: 3119-3127, 2010.

47. Wang G, Chan ES, Kwan BC, et al: Expression of microRNAs in the urine of patients with bladder cancer. Clin Genitourin Cancer 10: 106-113,2012.

48. Chiang YP, Song YX, Wang ZN, et al: microRNA-192,-194 and-215 are frequently downregulated in colorectal cancer. Exp Ther Med 3: 560-566, 2012.

49. Rossing M, Borup R, Henao R, et al: Down-regulation of microRNAs controlling tumourigenic factors in follicular thyroid carcinoma. J Mol Endocrinol 48: 11-23, 2012.

50. Wang LL, Zhang ZF, Li Q, et al: Ethanol exposure induces differential microRNA and target gene expression and teratogenic effects which can be suppressed by folic acid supplementation. Hum Reprod 24: 562-579, 2009.

51. Soares AR, Pereira PM, Ferreira V, et al: Ethanol exposure induces upregulation of specific microRNAs in zebrafish embryos. Toxicol Sci 127: 18-28, 2012.

52. Miranda RC, Pietrzykowski AZ, Tang Y, et al: MicroRNAs: master regulators of ethanol abuse and toxicity? Alcohol Clin Exp Res 34: 575-587, 2010. 